\title{
Article
}

\section{Effects of different footwear on kinetics, kinematics and muscle forces during the barbell back squat; an exploration using Bayesian modelling}

Sinclair, Jonathan Kenneth, Butters, Bobbie, Stone, Mark, Taylor, Paul John, Bentley, Ian and Edmundson, Christopher James

Available at http://clok.uclan.ac.uk/33233/

Sinclair, Jonathan Kenneth ORCID: 0000-0002-2231-3732, Butters, Bobbie, Stone, Mark ORCID: 0000-0003-0735-287X, Taylor, Paul John ORCID: 00000002-9999-8397, Bentley, Ian ORCID: 0000-0002-9086-2338 and Edmundson, Christopher James ORCID: 0000-0003-2275-7584 (2020) Effects of different footwear on kinetics, kinematics and muscle forces during the barbell back squat; an exploration using Bayesian modelling. Footwear Science, 12 (3). pp. 139-152. ISSN 1942-4280

It is advisable to refer to the publisher's version if you intend to cite from the work. http://dx.doi.org/10.1080/19424280.2020.1769202

For more information about UCLan's research in this area go to http://www.uclan.ac.uk/researchgroups/ and search for <name of research Group>.

For information about Research generally at UCLan please go to http://www.uclan.ac.uk/research/

All outputs in CLoK are protected by Intellectual Property Rights law, including Copyright law. Copyright, IPR and Moral Rights for the works on this site are retained by the individual authors and/or other copyright owners. Terms and conditions for use of this material are defined in the policies page. 


\title{
Effects of different footwear on kinetics, kinematics and muscle forces during the
} barbell back squat; an exploration using Bayesian modelling.

\author{
Jonathan Sinclairl ${ }^{1}$ Bobbie Butters ${ }^{1}$, Paul John Taylor ${ }^{2}$, Mark Stone $^{1}$, Ian Bentley ${ }^{1}$,
} Christopher James Edmundson ${ }^{1}$

1. Centre for Applied Sport \& Exercise Sciences, School of Sport \& Health Sciences, Faculty of Health \& Wellbeing, University of Central Lancashire.

2. School of Psychology, Faculty of Science \& Technology, University of Central Lancashire.

Keywords: Biomechanics, footwear, kinetics, kinematics, muscle forces.

\section{Abstract}

The current study aimed to explore the effects of different footwear on kinetics, kinematics and muscle forces during the barbell back squat in both male and female lifters using Bayesian modelling. Twelve male and twelve female lifters completed squats at $70 \%$ of their 1 repetition maximum, in four different footwear conditions (Adidas weightlifting shoe, Inov-8 weightlifting shoe, Cross-fit and minimal footwear). Three-dimensional kinematics were measured using an eight-camera motion analysis system, ground reaction forces using a force platform and muscle/ joint forces using musculoskeletal modelling techniques. Differences between footwear were examined using Bayesian 4 (FOOTWEAR) * 2 (GENDER) mixed ANOVA's. Peak quadriceps force was greater in the Adidas (male=89.78/female=70.56N/kg), Cross-fit $\quad($ male $=92.41 /$ female $=70.82 \mathrm{~N} / \mathrm{kg}) \quad$ and $\quad$ Inov-8 $\quad($ male $=91.57 /$ female $=68.21 \mathrm{~N} / \mathrm{kg})$ conditions compared to minimal footwear $($ male $=82.61 /$ female $=64.40 \mathrm{~N} / \mathrm{kg})$. In addition, peak patellofemoral stress and patellar tendon forces were greater in the Adidas (patellar tendon force: male $=64.67 /$ female $=42.89 \mathrm{~N} / \mathrm{kg}$

$\&$ patellofemoral

stress: 
male $=143.21 /$ female $=118.92 \mathrm{KPa} / \mathrm{kg}$ ), Cross-fit (patellar tendon force:

male $=67.89 / \mathrm{female}=43.52 \mathrm{~N} / \mathrm{kg} \&$ patellofemoral stress: male $=146.02 / \mathrm{female}=114.73 \mathrm{KPa} / \mathrm{kg}$ ) and Inov-8 (patellar tendon force: male $=64.08 / \mathrm{female}=41.04 \mathrm{~N} / \mathrm{kg} \&$ patellofemoral stress: male $=193.09 / \mathrm{female}=169.09 \mathrm{KPa} / \mathrm{kg}$ ) conditions compared to minimal footwear (patellar tendon force: $\quad$ male $=56.75 /$ female $=39.92 \mathrm{~N} / \mathrm{kg} \quad \&$ patellofemoral stress: male $=134.06 / \mathrm{female}=108.91 \mathrm{KPa} / \mathrm{kg}$ ). Finally, angular ROM was greater in the minimal footwear $\left(\right.$ male $=28.04 /$ female $\left.=33.75^{\circ}\right)$ compared to the Adidas $\left(\right.$ male $=26.85 /$ female $\left.=30.73^{\circ}\right)$ and Inov-8 (male $=26.92 /$ female $\left.=32.63^{\circ}\right)$ conditions. The findings from the current investigation therefore indicate that weightlifting footwear may be able to enhance lower extremity muscle development and improve squat biomechanics owing to a reduced trunk angular ROM; however, this is likely to be at the expense of increased knee joint loading.

\section{Introduction}

The barbell back squat is a fundamental exercise within the scientific discipline of strength and conditioning, and one of the three competition lifts associated with the sport of powerlifting (Lake et al., 2012). The primary function of the squat is to recruit and strengthen the lower extremity musculature; with predominant activation of the quadriceps, hamstrings, tibialis anterior, gluteus, soleus and gastrocnemius (Robertson et al., 2008). There is also significant isometric recruitment of the supporting musculature such as the abdominals, trapezius and rhomboids to promote postural control in the trunk during the squat (Schoenfeld, 2010). Importantly, the barbell squat is functionally similar to a wide range of sports movements and is thus included in the majority of strength training routines with the goal of enhancing athletic performance (Schoenfeld, 2010). 
Like most strength exercises, the barbell squat movement is associated with a number of technique variations (Whitting et al., 2016). Regardless, the movement originates from an upright/ standing position, with near maximal extension of the hip and knee joints and the ankle in a neutral position. The squat is initiated through flexion of the hip and knee joints, and dorsiflexion of the ankle. When the required depth is attained, the lifter subsequently extends the hip and knee joints and plantarflexes the ankle in order to reverse the direction of the squat and return to original position. One of the primary limiting factors in regards to the effective execution of the barbell squat, is a lack of sagittal plane mobility at the ankle (Whitting et al., 2016). This can negatively influence lifting mechanics, as it forces the lifter to utilize increased trunk angle, in order to achieve the desired squat depth (Whitting et al., 2016). This is considered to be an error in technique linked to the aetiology of injury due to shear and compressive loading in the lumbar vertebrae (Swinton et al., 2012).

The International Weightlifting Federation 'technical and competition rule' 4.4.3 designates that all competitors must wear sport footwear, and thus it is commonplace for the barbell squat to be performed using a range of different shoe modalities (Sinclair et al., 2015a). The most common footwear amongst recreational lifters are traditional athletic footwear (Sinclair et al., 2015a). However, in athletes and weightlifters more accustomed to resistance training, designated weightlifting shoes are considered an important piece of equipment for training and competition (Sato et al., 2012). Weightlifting shoes feature a rigid non-deformable sole with a raised heel section (Legg et al., 2016). The raised heel section is designed to attenuate the influence of sagittal plane ankle mobility and allow lifters to reduce the extent of their trunk angle, whilst still attaining the required squat depth (Whitting et al., 2016). In addition, with the expansion of Cross-fit as a sporting discipline in its own right, footwear specific to this discipline is becoming increasing popular. Cross-fit specific footwear represents a hybrid shoe 
condition, designed to incorporate the stability characteristics of a weightlifting shoe with the cushioning and flexibility features of a running shoe (Sinclair \& Sant, 2017). Finally, as highlighted by Sinclair et al., (2015a), minimalist footwear are also a popular footwear modality for squatting. Shorter et al, (2011) proposed that minimalist footwear can be effective for squatting, as they may enhance lower limb proprioception and also provide improve force generation from the foot ground interface.

The effects of different footwear on the mechanics of the barbell squat have received some attention in biomechanics and strength and conditioning literature. Shorter et al., (2011) showed that peak power production during the back squat at $80 \%$ of 1 rep max was greater in traditional athletic footwear and barefoot conditions in relation to minimalist footwear. Similarly, Sato et al., (2012) revealed that the trunk angle was significantly greater when performing the back squat barefoot in comparison to traditional athletic footwear. Whitting et al., (2016) showed that peak ankle dorsiflexion was significantly greater when performing the back squat whilst wearing traditional athletic footwear compared to weightlifting shoes. Legg et al., (2016) found that weightlifting footwear mediated significant reductions in ankle and trunk angulation, and increased knee flexion and sagittal plane knee moments. The observations of Sinclair et al., (2015a) revealed that in comparison to squatting barefoot, traditional athletic footwear was associated with increased squat depth, knee flexion and electrical recruitment of the rectus remoris, with no differences noted for the weightlifting footwear. However, the current literature in regards to the influence of different footwear on the mechanical characteristics of the squat has examined only limited biomechanical parameters, and has routinely examined only one gender as part of the experimental design. 
Furthermore, Bayesian analyses have become considerably more prevalent and practicable in the last several years (Pullenayegum \& Thabane, 2009). Although, despite their prospective benefits (Ashby, 2006) and the excess of statistical publications supporting their adoption, their utilization in biomechanical analyses remains limited. To date there has yet to be any biomechanical investigation which has examined the effects of different weightlifting footwear on kinetics, kinematics and muscle forces during the barbell back squat using Bayesian analyses. Therefore, the current study aimed to provide a comprehensive biomechanical exploration of the barbell back squat, whilst wearing different weightlifting footwear; using a sample of both male and female lifters via a Bayesian modelling approach. An investigation of this nature may provide important information to weightlifters and strength and conditioning practitioners regarding the most appropriate footwear for the barbell back squat.

\section{Methods}

\section{Participants}

Twelve males (age: $28.65 \pm 6.27$ years, stature: $176.95 \pm 5.52 \mathrm{~cm}$, mass: $83.54 \pm 15.05 \mathrm{~kg}$ and 1RM back squat: $132.64 \pm 23.73 \mathrm{~kg}$ ) and twelve females (age: $27.11 \pm 5.83$ years, $162.83 \pm$ $7.93 \mathrm{~cm}$, mass: $66.33 \pm 6.69 \mathrm{~kg}$ and $1 \mathrm{RM}$ back squat $99.31 \pm 22.22 \mathrm{~kg}$ ) took part in this investigation. Participants were all practiced in squat lifting with a minimum of 5 years of resistance training experience. All were free from musculoskeletal pathology at the time of data collection and provided written informed consent. The procedure used for this investigation was approved by an institutional ethical committee $(\mathrm{REF}=458)$.

\section{Footwear}


The footwear used during this study consisted of four conditions Adidas (Powerlift 3.0), Inov$15 \mathrm{~mm}$ and a heel drop of $9 \mathrm{~mm}$. The Inov- 8 footwear had an average mass of $0.335 \mathrm{~kg}$, heel thickness of $17 \mathrm{~mm}$ and a heel drop of $15 \mathrm{~mm}$. The Cross-fit footwear had an average mass of $0.278 \mathrm{~kg}$, heel thickness of $13 \mathrm{~mm}$ and a heel drop of $5 \mathrm{~mm}$. Finally, the minimalist footwear had an average mass of $0.158 \mathrm{~kg}$, heel thickness of $5 \mathrm{~mm}$ and a heel drop of $0 \mathrm{~mm}$. After completion of data collection each participant was asked to subjectively indicate which of the four footwear conditions that they preferred.

\section{Procedure}

Three-dimensional kinematics were captured using an eight-camera motion analysis system (Qualisys Medical AB, Goteburg, Sweden), which sampled at $250 \mathrm{~Hz}$. In addition, to capture ground reaction force (GRF) data, piezoelectric force plates (Kistler, Kistler Instruments Ltd., Alton, Hampshire) were adopted, which collected data at $1000 \mathrm{~Hz}$. Kinematics and GRF information were synchronously collected using an analogue to digital interface board, and the camera system was calibrated prior to each data collection session.

Body segments were modelled in 6 degrees of freedom, using the principles of the calibrated anatomical systems technique (Cappozzo et al., 1995). The anatomical frames of the torso, pelvis, thighs, shanks and feet were delineated via the retroreflective markers described by Sinclair et al., (2015a). Carbon-fiber tracking clusters comprising of four non-linear retroreflective markers were positioned onto the thigh and shank segments. In addition to these the foot segments were tracked via the calcaneus, first metatarsal and fifth metatarsal, the pelvic 
segment using the PSIS and ASIS markers and the torso via C7, T12 and xiphoid process. The centres of the ankle and knee joints were delineated as the mid-point between the malleoli and femoral epicondyle markers (Graydon et al., 2015; Sinclair et al., 2015b), whereas the hip joint centre was obtained using the positions of the ASIS markers (Sinclair et al., 2014).

Static calibration trials were obtained with the participant in the anatomical position, in order for the anatomical positions to be referenced in relation to the clusters/markers, following which those not required for dynamic data were removed. The $\mathrm{Z}$ (transverse) axis was oriented vertically from the distal segment end to the proximal segment end. The Y (coronal) axis was oriented in the segment from posterior to anterior. Finally, the $\mathrm{X}$ (sagittal) axis orientation was determined using the right-hand rule and was oriented from medial to lateral.

\section{Squat protocol}

For data collection, all participants presented to the laboratory 48 hours after their previous lower-body resistance training session. Before the measured squats were initiated, a general warm up was completed, followed by squat warm-up sets with 30 and $50 \%$ of 1RM (Lahti et al., 2019). Participants completed five continuous high bar back squat repetitions at $70 \%$ of their 1RM, in each if the four experimental footwear conditions using a counterbalanced order. A rest period of 3 minutes was enforced between each footwear condition (Lake et al., 2012). A load of 70\% of 1RM was selected in accordance with Sinclair et al., (2015), and was deemed to be characteristic of a typical training load, whilst still maintaining the levels of repeatability necessary obtain a representative data set. In accordance with the National Strength \& Conditioning (NSCA) guidelines, lifters were instructed to descend in a controlled manner, keep both feet flat on the floor, preserve proper breath control and maintain a constant/ stable 
pattern of motion for each repetition. Participants were not instructed to achieve a predetermined depth because the aim of the current investigation was to examine differences between footwear, therefore participants were free to preform within their natural range of motion capabilities under each condition (Legg et al., 2016). Each participant was examined visually by an NSCA certified strength and conditioning specialist.

\section{Processing}

Marker trajectories were digitized using Qualisys Track Manager, and then exported as C3D files. Kinematic parameters were quantified using Visual 3-D (C-Motion Inc, Gaithersburg, USA). Marker data was smoothed using a low-pass Butterworth 4th order zero-lag filter at a cut off frequency of $6 \mathrm{~Hz}$ (Sinclair et al., 2015a). Kinematics of the hip, knee, ankle and trunk were quantified using an XYZ cardan sequence of rotations, and joint moments using newtoneuler inverse dynamics. All data were normalized to $100 \%$ of the squat via the first and second instances of maximal hip extension (Sinclair et al., 2015a). A further time point at the midpoint of the lift that separated the eccentric and concentric phases was identified using the lowest position of the model centre of mass (Sinclair et al., 2019). Three-dimensional kinematic measures from the hip, knee, ankle which were extracted for statistical analysis were 1) peak angle and 2) angular range of motion (ROM) from initiation to peak angle. In addition, sagittal plane measures from the trunk of 1) peak angle and 2) angular range of motion (ROM) were also extracted.

Muscle forces were estimated using processes adopted previously for the quantification of muscle kinetics during the barbell back squat (Sinclair et al., 2019). Quadriceps force was estimated using a musculoskeletal model (van Eijden et al., 1986). The quadriceps force was 
resolved by dividing the knee flexor moment from inverse-dynamics by the moment arm of the quadriceps muscle. The moment arm of the quadriceps was predicted by fitting a 2 nd order polynomial curve to the knee flexion angle-quadriceps moment arm data presented by van Eijden et al., (1986).

Hamstring, gluteus maximus, soleus and gastrocnemius forces were also estimated using musculoskeletal modelling approaches (Willson et al., 2015). The hamstring and gluteus maximus forces were firstly predicted using the hip extensor moment from inverse-dynamics and the estimated hamstring and gluteus maximus cross-sectional areas, which determined the extent of the joint moment attributable to each muscle (Ward et al., 2009). The hamstring muscle forces were then estimated by dividing the hip extensor moment attributable to each muscle by the muscle moment arms (Németh \& Ohlsén, 1985). The moment arms were predicted by fitting a 2 nd order polynomial curve to the hip flexion angle-hamstrings/ gluteus maximus moment arm data of Nemeth \& Ohlsen, (1985). In addition, the gastrocnemius and soleus forces were predicted firstly by quantifying the ankle plantarflexor force, which was resolved by dividing the dorsiflexion moment from inverse dynamics by the Achilles tendon moment arm. The Achilles tendon moment arm was estimated by fitting a 2 nd order polynomial curve to the dorsiflexion angle-Achilles tendon moment arm data of Self \& Paine (2001).

Plantarflexion force accredited to the gastrocnemius and soleus muscles was calculated via the estimated cross-sectional area of each muscle relative to the total volume of the triceps-surae (Ward et al., 2009). 
gastrocnemius forces were extracted for statistical analysis. In addition, the integral (impulse) of these forces $(\mathrm{N} / \mathrm{kg} \cdot \mathrm{s})$ were calculated during the eccentric and concentric phases using a trapezoidal function. Finally, the peak rate of force development (RFD) at each of the quadriceps, hamstring, gluteus maximus soleus and gastrocnemius muscles during the concentric phase was also extracted by obtaining the peak increase in muscle force between adjacent data points using the first derivative function within Visual 3D (N/kg/s).

In addition, internal hip and knee joint compressive/ shear forces were also calculated using the joint force function within Visual 3D (Sinclair et al., 2019). Furthermore, patellar tendon force was estimated using a model adapted from Janssen et al., (2013). The knee flexion moment quantified using inverse dynamics was divided by the predicted moment arm of the patellar tendon. The tendon moment arm was quantified by fitting a 2 nd order polynomial curve to the knee flexion angle-patellar tendon moment arm data provided by Herzog \& Read, (1993).

The patellofemoral joint reaction force was estimated by multiplying the quadriceps force (described above) by a constant which was obtained via the below equation using the data of van Eijden et al., (1986). Following this, patellofemoral stress was calculated by dividing the patellofemoral joint reaction force by the predicted patellofemoral contact area. Patellofemoral contact areas were obtained by fitting a 2 nd order polynomial curve to the sex specific knee flexion angle-patellofemoral contact area data of Besier et al., (2005).

constant $=\left(0.462+0.00147 *\right.$ knee flexion angle ${ }^{2}-0.0000384 *$ knee flexion angle $\left.^{2}\right) /(1$ $-0.0162 *$ knee flexion angle $+0.000155 *$ knee flexion angle ${ }^{2}-0.000000698 *$ knee 
242 The peak hip/ knee joint compressive/ shear force, patellar tendon force, patellofemoral force $243(\mathrm{~N} / \mathrm{kg})$ and patellofemoral stress $(\mathrm{KPa} / \mathrm{kg})$ were extracted following normalization to body 244 mass. The instantaneous loading rate of the aforementioned joint force $(\mathrm{N} / \mathrm{kg} / \mathrm{s})$ and stress $245(\mathrm{KPa} / \mathrm{kg} / \mathrm{s})$ parameters was calculated by obtaining the peak increase force/ stress between adjacent data points, using the first derivative function within Visual 3D. In addition, the impulse of the aforementioned parameters $(\mathrm{N} / \mathrm{kg} \cdot \mathrm{s}$ and $\mathrm{KPa} / \mathrm{kg} \cdot \mathrm{s})$ were calculated during the entire squat movement using a trapezoidal function.

From the force plate, peak normalized vertical GRF (N/kg) was extracted. The RFD of the vertical GRF (N/kg/s) in the concentric phase was also calculated, by obtaining the peak increase in vertical GRF force between adjacent data points again using the first derivative function within Visual 3D. In addition, the impulse of the vertical, medio-lateral and anterioposterior GRF's $(\mathrm{N} / \mathrm{kg} \cdot \mathrm{s})$ were calculated during both the eccentric and concentric phases of the lift via a trapezoidal function. Furthermore, the peak power applied to the centre of mass $(\mathrm{W} / \mathrm{kg}$ ) during concentric phase was extracted using a product of the vertical GRF and the vertical velocity of the model centre of mass within Visual 3D. The total lift duration (s) was also calculated using the time difference from the initiation to the end of each repetition, and the absolute duration of the eccentric/ concentric phases (s) was also extracted. Finally, the squat depth was quantified by deducting the model centre of mass vertical position at the end of the descent phase, from that observed at the initiation of the movement. This value was then expressed as a function of each lifters total stature (\%). 
Descriptive statistics of means and standard deviations were obtained for each outcome measure. Differences in biomechanical parameters between each of the four footwear conditions were examined using Bayesian 4 (FOOTWEAR) * 2 (GENDER) mixed ANOVA's with default prior scales using JASP software 0.10.2 (Wagenmakers et al., 2018). Bayesian factors (BF) were used to explore the extent to which the data supported the alternative $\left(\mathrm{H}_{1}\right)$ hypothesis. Bayes factors were interpreted in accordance with the recommendations of Jeffreys, (1961), with values above 3 indicating sufficient evidence in support of $\mathrm{H}_{1}$. In the event of a main effect of FOOTWEAR, post-hoc Bayesian comparisons were conducted between each footwear condition and in the event of a significant interaction Bayesian simple main effects were employed (Wagenmakers et al., 2018). In addition, information from participants' subjective ratings in relation to their preferred footwear condition were explored using Chi-Square $\left(X^{2}\right)$ tests using SPSS v26 (IBM, SPSS, USA).

\section{Results}

Kinetic and temporal parameters

@@@TABLE 1 NEAR HERE@@@

For the maximum vertical GRF, there was substantial evidence of a main effect of FOOTWEAR. Post-hoc comparisons indicated that there was substantial evidence indicating that the maximum GRF was greater in the Inov- 8 footwear compared to minimal $(\mathrm{BF}=4.41)$ (Table 1). For the eccentric medio-lateral GRF, there was decisive evidence to support a main effect of FOOTWEAR. Post-hoc comparisons indicated that there was strong-very strong evidence indicating that the eccentric medio-lateral GRF was greater in minimal footwear compared to the Adidas $(\mathrm{BF}=35.67)$, Cross-fit $(\mathrm{BF}=6.62)$ and Inov-8 $(\mathrm{BF}=93.32)$ conditions 
(Table 1). For the eccentric vertical GRF there was substantial evidence of a main effect of FOOTWEAR. Post-hoc comparisons indicated that there was substantial evidence to show that the eccentric vertical GRF was greater in minimal footwear compared to the Cross-fit $(\mathrm{BF}=$ 3.11) condition (Table 1). For the concentric medio-lateral GRF, there was decisive evidence of a main effect of GENDER, showing that the concentric medio-lateral GRF was greater in females, and also very strong evidence in support of a main effect of FOOTWEAR. Post-hoc comparisons indicated that there was substantial evidence to show that the concentric mediolateral GRF was greater in minimal footwear compared to the Adidas $(\mathrm{BF}=14.39)$ and Inov$8(\mathrm{BF}=25.43)$ condition (Table 1$)$. For peak power there was substantial evidence in support of a FOOTWEAR*GENDER interaction (Table 1). Bayesian simple main effects showed that in females there was no evidence of a main effect of FOOTWEAR $(\mathrm{BF}=0.26)$ but in males there was substantial evidence $(\mathrm{BF}=6.96)$, with post-hoc comparisons showing that peak power was greater in the Inov-8 $(\mathrm{BF}=3.01)$ and Cross-fit $(\mathrm{BF}=3.31)$ conditions compared to minimal footwear.

For the total squat time, there was strong evidence of a main effect of FOOTWEAR. Post-hoc comparisons indicated that there was substantial-very strong evidence indicating that the total squat time was greater in the minimal footwear compared to the Adidas $(\mathrm{BF}=38.47)$ and Cross-fit $(\mathrm{BF}=5.25)$ (Table 1). Finally, for the eccentric squat time, there was very strong evidence to support a main effect of FOOTWEAR. Post-hoc comparisons indicated that there was substantial evidence that the eccentric squat time was greater in the minimal footwear compared to the Adidas $(\mathrm{BF}=8.24)$, Inov-8 $(\mathrm{BF}=5.09)$ and Cross-fit $(\mathrm{BF}=7.59)$ (Table 1$)$. 
315 For the peak quadriceps force, there was substantial evidence of a main effect of GENDER, showing that the quadriceps force was greater in males, and also decisive evidence in support of a main effect of FOOTWEAR. Post-hoc comparisons indicated that there was substantialvery strong evidence that the quadriceps force was greater in the Adidas ( $\mathrm{BF}=15.89)$, Crossfit $(\mathrm{BF}=4.06)$ and Inov-8 $(\mathrm{BF}=62.63)$ conditions compared to minimal footwear $($ Table 2$)$. Finally, for the quadriceps concentric impulse there was very strong evidence of a main effect of FOOTWEAR. Post-hoc comparisons indicated that there was substantial-very strong evidence that the quadriceps concentric impulse was greater in the Adidas $(\mathrm{BF}=6.40)$ and Inov-8 $(\mathrm{BF}=37.09)$ conditions compared to the minimal footwear (Table 2).

Joint kinetics

For peak patellofemoral joint reaction force, there was substantial evidence of a main effect of GENDER, showing that the patellofemoral force was greater in males, and also decisive evidence in support of a main effect of FOOTWEAR. Post-hoc comparisons indicated that there was substantial-very strong evidence that peak patellofemoral force was greater in the Adidas $(\mathrm{BF}=16.49)$, Cross-fit $(\mathrm{BF}=3.32)$ and Inov-8 $(\mathrm{BF}=74.15)$ conditions compared to minimal footwear and in the Inov-8 compared to Cross-fit $(\mathrm{BF}=3.21)$ (Table 3). For peak patellofemoral stress, there was substantial evidence of a main effect of GENDER, showing that patellofemoral stress was greater in males, and also decisive evidence in support of a main 
effect of FOOTWEAR. Post-hoc comparisons indicated that there was substantial-very strong evidence to show that patellofemoral stress was greater in the Adidas $(\mathrm{BF}=8.57)$, Cross-fit $(\mathrm{BF}=3.33)$ and Inov-8 $(\mathrm{BF}=6.47)$ conditions compared to the minimal footwear (Table 3$)$. Finally, for peak patellar tendon force, there was strong evidence of a main effect of GENDER, showing that tendon force was greater in males, and also decisive evidence in support of a main effect of FOOTWEAR. Post-hoc comparisons indicated that there was substantial-decisive evidence that peak patellar tendon force was greater in the Adidas $(\mathrm{BF}=3.29)$, Cross-fit (BF $=272.27)$ and Inov-8 $(\mathrm{BF}=18.64)$ compared to the minimal footwear (Table 3$)$.

Three-dimensional kinematics

@@@TABLE4 NEAR HERE@@@

For peak trunk angle there was decisive evidence in support of a main effect of FOOTWEAR.

Post-hoc comparisons indicated that there was strong-decisive evidence that the trunk angle was greater in the minimal $(\mathrm{BF}=178.35)$ and Cross-fit $(\mathrm{BF}=22.10)$ conditions compared to Inov-8 (Table 4). In addition, for trunk ROM there was decisive evidence of a main effect of FOOTWEAR. Post-hoc comparisons indicated that there was decisive evidence that trunk ROM was greater in the minimal footwear compared to Adidas $(\mathrm{BF}=292.32)$ and Inov-8 $(\mathrm{BF}$ $354=12801.55)$ conditions (Table 4).

For peak knee flexion, there was substantial evidence of a main effect of GENDER, showing that the peak flexion was greater in males, and also decisive evidence in support of a main effect of FOOTWEAR. Post-hoc comparisons indicated that there was substantial-decisive 
evidence that peak flexion was greater in the Inov- 8 footwear compared to minimal $(\mathrm{BF}=3.89)$ and Cross-fit $(\mathrm{BF}=107.56)$ conditions (Table 4). For the sagittal plane knee ROM there was substantial evidence of a main effect of FOOTWEAR. Post-hoc comparisons indicated that there was substantial-strong evidence that the ROM was greater in the Inov-8 footwear compared to the minimal $(\mathrm{BF}=6.46)$ and Cross-fit $(\mathrm{BF}=19.44)$ conditions (Table 4).

For peak knee internal rotation there was substantial evidence of a main effect of GENDER, which showed that the peak internal rotation was greater in males (Table 4).

For the sagittal plane ankle ROM there was decisive evidence of a main effect of GENDER, showing that the ROM was greater in males, and also substantial evidence in support of a main effect of FOOTWEAR. Post-hoc comparisons indicated that there was decisive evidence that the ROM was greater in the Inov-8 footwear compared to the minimal $(\mathrm{BF}=1353.23)$ and Cross-fit $(\mathrm{BF}=22210.53)$, and similarly in the Adidas compared to minimal $(\mathrm{BF}=121.51)$ and Cross-fit $(\mathrm{BF}=5084.53)$ conditions (Table 4).

For the peak ankle external rotation there was substantial evidence of a main effect of FOOTWEAR. Post-hoc comparisons indicated that there was strong-decisive evidence that peak external rotation was greater in the minimal compared to the Cross-fit $(\mathrm{BF}=2405.12)$, Adidas $(\mathrm{BF}=40574.40)$ and Inov-8 $(\mathrm{BF}=55476.56)$, and in the Cross-fit compared to the Adidas $(\mathrm{BF}=14.74)$ and Inov-8 $(\mathrm{BF}=5380.61)$ conditions. 
382 In male lifters 9 participants preferred the Adidas footwear and 3 preferred the minimal 383 footwear. The chi-squared test was significant $\left(X^{2}=15.00, \mathrm{P}<0.05\right)$ and indicates that there was a significant preference towards the Adidas condition. In female lifters 4 participants preferred the Adidas footwear, 4 preferred the Inov-8, 2 preferred the minimal and 1 preferred the Cross-fit. The chi-squared test was non-significant $\left(X^{2}=2.01, \mathrm{P}>0.05\right)$ in females.

\section{Discussion}

The aim of the current investigation was to provide a comprehensive exploration of the barbell back squat, whilst wearing different weightlifting footwear in both male and female lifters using Bayesian modelling. This is the first study to broadly explore the influence of different footwear typically utilized for weightlifting on the mechanics of the barbell back squat. This analysis may therefore provide information regarding the most appropriate footwear for the barbell back squat.

Importantly, the current investigation showed that the different footwear examined as part of this study influenced barbell back squat kinematics. Specifically, it was revealed that peak trunk angle and trunk ROM were greater in the minimal and Cross-fit footwear in comparison to both weightlifting shoes. It is proposed that this finding relates to the ankle dorsiflexion ROM, mediated by the elevated heels found in the weightlifting shoes. The observation of increased trunk angle magnitude opposes those of Whitting et al., (2016) who found no effect of footwear on trunk kinematics, yet agrees with those of Legg et al., (2016) and Sato et al., (2012) who showed that the trunk angle was significantly reduced when wearing weightlifting shoes. A more vertically orientated trunk is desirable during squatting, owing to increased shear and compressive loading in the lumbar vertebrae when the trunk angle increases (Swinton et 
risk due to shear and compressive loading.

The current study also showed that knee flexion magnitude was statistically greater in the Inov8 shoes. This observation apposes those of Whitting et al., (2016) and Sato et al., (2012) who found no effect of footwear on knee joint kinematics, but agrees with the findings of Legg et al., (2016) who found that weightlifting footwear with significantly increased knee flexion. It is proposed that increases in knee flexion were mediated through the raised heels in the which mediate alterations in squat depth, as reported be Legg et al., (2016). This observation may be linked to dissimilarities in the manner by which squat depth was quantified between studies. However, the most likely scenario is that the additional trunk angle observed in the non-weight lifting footwear was utilized as a compensatory mechanism to lower the centre of mass, counteracting the reduction in knee flexion. The current study therefore shows that the alterations in lower extremity kinematics generated by the weightlifting footwear may provide a mechanism by which the desired squat depth can be achieved, without the potential negative effects of increased trunk angulation (Swinton et al., 2012).

Importantly, the current investigation showed that muscle force parameters were significantly influenced by the experimental footwear. Specifically, weightlifting and Cross-fit footwear increased the peak quadriceps force and the quadriceps concentric impulse compared to the minimal condition. This observation concurs with those of Legg et al., (2016) who showed 
using the sagittal knee joint moment, that weightlifting footwear enhanced the demands on the knee extensors. It is proposed that this observation was mediated via the increases in knee flexion and heel lift in the aforementioned footwear compared to the minimal condition, which served to enhance the demands placed on the quadriceps due to the more posterior orientation of the GRF vector in relation to the knee joint centre (Legg et al., 2016). Enhanced quadriceps muscle forces in the weightlifting and Cross-fit footwear conditions was apparent in spite of the same absolute load being lifted; and skeletal muscle mechanical tension is the primary driver for hypertrophy (Schoenfeld, 2010). Furthermore, the cross-sectional area is the key determiner of maximum muscle force production (Vigotsky et al., 2015), and training stimuli govern the magnitude of skeletal muscle adaptive responses (Winwood et al., 2012). Therefore, as weightlifting and Cross-fit footwear enhanced quadriceps recruitment, this indicates that their utilization may be advisable in athletes seeking to maximise training adaptations.

The current study also supported the notion that different footwear can significantly influence the characteristics of the squat itself. Firstly, it was revealed that the minimal footwear significantly affected the temporal aspects of the squat, by increasing the total lift duration and the duration of the eccentric phase. It is proposed that the increased duration of the eccentric phase was responsible for the enhanced vertical impulse during this aspect of the movement, although there were no subsequent increases during the concentric phase, rather it was the medially orientated impulse that were increased in the minimal footwear during both phases. notion that there may be a reduced transfer of effective i.e. vertical GRF from the foot-ground interface in these footwear owing to their reduced outsole stiffness in relation to the other 
for this, as peak power applied to the centre of mass during the ascent phase was reduced attenuated in the minimal footwear; although this was evident in male lifters only.

With regards to the observations garnered from the joint loading analyses, this study showed that neither hip or knee joint compressive/ shear loading were influenced by the experimental footwear. However, this investigation did show that both patellofemoral and patellar tendon loading parameters were reduced in the minimal footwear. Patellofemoral and patellar tendon loading are considered to be the primary biomechanical mechanisms linked to the initiation/ progression of degenerative patellofemoral/ patellar tendon pathologies (Farrokhi et al., 2011; Rudavsky \& Cook, 2014). Therefore, the current investigation indicates that minimal footwear may reduce the biomechanical mechanisms linked to the aetiology of knee pathologies.

Finally, the statistical analyses of subjective footwear preferences indicated that in male lifters there was a significant preference towards the Adidas footwear; yet in females there was no statistical preference for any of the experimental footwear. This observation disagrees with those of Sinclair et al., (2015) who showed that in a sample of novice male lifters there was a statistical preference for barefoot squatting over weightlifting and traditional athletic footwear. This divergence between studies may be due the squatting experience of the lifters in each investigation and indicates that the requirement/ preference for specific footwear in order to perform the barbell squat may be gender and experience specific. Further experimental analyses are required before this proposition can be substantiated.

A limitation of the current investigation is that the lifters did not habitually use all of the 477 footwear examined in the current investigation. Therefore, it remains unknown as to whether 
the observations from the current work may have been different had participants habitually used the experimental footwear. Therefore, it may be prudent for a future investigation to examine the biomechanics of the squat across groups of lifters that habitually utilize different weightlifting footwear. In addition, as the current investigation used a musculoskeletal modelling-based procedure to estimate muscle kinetics, this may serve as a limitation. Numerous assumptions are made in the construction of musculoskeletal models (Delp et al., 2007), which may influence the predicted muscle forces. However, as in-vivo measurements of muscle forces remain unfeasible, the current procedure represents the most practicable technique for the quantification muscle forces during dynamic movements.

\section{Conclusion}

In conclusion, the effects of different footwear on kinetics, kinematics and muscle forces during the barbell back squat have received limited research attention. Therefore, the present study adds to the current scientific knowledge, by providing a comprehensive exploration of the biomechanical effects of different footwear during the squat in male and female lifters using Bayesisn modelling. Importantly, weightlifting footwear enhanced quadriceps muscle force parameters compared to minimal footwear and were also associated with increased patellofemoral and patellar tendon loading. In addition, the current investigation importantly revealed that the trunk angle and trunk ROM were reduced in the weightlifting footwear. The findings from the current investigation indicate that weightlifting footwear may be able to enhance lower extremity muscle development and improve squat biomechanics owing to a reduced trunk angulation; however, this is likely to be at the expense of increased knee joint loading. 
1. Ashby, D. (2006). Bayesian statistics in medicine: a 25-year review. Statistics in medicine, 25(21), 3589-3631.

2. Besier, T.F., Draper, C.E., Gold, G.E., Beaupré, G.S., \& Delp, S.L. (2005). Patellofemoral joint contact area increases with knee flexion and weight-bearing. Journal of Orthopaedic Research, 23(2), 345-350.

3. Cappozzo, A., Catani, F., Della Croce, U., \& Leardini, A. (1995). Position and orientation in space of bones during movement: anatomical frame definition and determination. Clinical biomechanics, 10(4), 171-178.

4. Delp, S. L., Anderson, F. C., Arnold, A. S., Loan, P., Habib, A., John, C. T., ... \& Thelen, D. G. (2007). OpenSim: open-source software to create and analyze dynamic simulations of movement. IEEE transactions on biomedical engineering, 54(11), 19401950.

5. Farrokhi, S., Keyak, J.H., \& Powers, C.M. (2011). Individuals with patellofemoral pain exhibit greater patellofemoral joint stress: a finite element analysis study. Osteoarthritis and Cartilage, 19(3), 287-294.

6. Graydon, R.W., Fewtrell, D.J., Atkins, S., \& Sinclair, J.K. (2015). The test-retest reliability of different ankle joint center location techniques. Foot and ankle online journal, 1(11), 10-15.

7. Herzog, W., \& Read, L.J. (1993). Lines of action and moment arms of the major forcecarrying structures crossing the human knee joint. Journal of Anatomy, 182(Pt 2), 213.

8. Janssen, I., Steele, J.R., Munro, B.J., \& Brown, N. A. (2013). Predicting the patellar tendon force generated when landing from a jump. Medicine and Science in Sports and Exercise, 45(5), 927-934. 
9. Jeffreys H. Theory of probability (3rd Ed.). 1961. Oxford, UK: Oxford University Press.

10. Lahti, J., Hegyi, A., Vigotsky, A.D., \& Ahtiainen, J.P. (2019). Effects of barbell back squat stance width on sagittal and frontal hip and knee kinetics. Scandinavian journal of medicine \& science in sports, 29(1), 44-54.

11. Lake, J.P., Carden, P.J., \& Shorter, K.A. (2012). Wearing knee wraps affects mechanical output and performance characteristics of back squat exercise. The Journal of Strength \& Conditioning Research, 26(10), 2844-2849.

12. Legg, H.S., Glaister, M., Cleather, D.J., \& Goodwin, J.E. (2016). The effect of weightlifting shoes on the kinetics and kinematics of the back squat. Journal of Sports Sciences, 35(5), 508-515.

13. Németh, G., \& Ohlsén, H. (1985). In vivo moment arm lengths for hip extensor muscles at different angles of hip flexion. Journal of biomechanics, 18(2), 129-140.

14. Pullenayegum, E. M., \& Thabane, L. (2009). Teaching Bayesian statistics in a health research methodology program. Journal of Statistics Education, 17(3), 21-23.

15. Robertson, D.G.E., Wilson, J M. J., \& Pierre, T. A. S. (2008). Lower extremity muscle functions during full squats. Journal of Applied Biomechanics, 24(4), 333-339.

16. Rudavsky, A., \& Cook, J. (2014). Physiotherapy management of patellar tendinopathy (jumper's knee). Journal of physiotherapy, 60(3), 122-129.

17. Sato, K., Fortenbaugh, D., Hydock, D.S., \& Heise, G D. (2012). Comparison of back squat kinematics between barefoot and shoe conditions. International Journal of Sports Science \& Coaching, 8(3), 571-578.

18. Schoenfeld, B.J. (2010). Squatting kinematics and kinetics and their application to exercise performance. The Journal of Strength \& Conditioning Research, 24(12), 34973506. 
19. Self, B.P., \& Paine, D. (2001). Ankle biomechanics during four landing techniques. Medicine and science in sports and exercise, 33(8), 1338-1344.

20. Shorter, K., Lake, J., Smith, N., \& Lauder, M. (2011). Influence of the foot-floor interface on squatting performance. Portuguese Journal of Sport Sciences, 11, 385-388.

21. Sinclair, J., Taylor, P. J., Currigan, G., \& Hobbs, S. J. (2014). The test-retest reliability of three different hip joint centre location techniques. Movement \& Sport SciencesScience \& Motricité, (83), 31-39.

22. Sinclair, J., McCarthy, D., Bentley, I., Hurst, H. T., \& Atkins, S. (2015a). The influence of different footwear on 3-D kinematics and muscle activation during the barbell back squat in males. European journal of sport science, 15(7), 583-590.

23. Sinclair, J., Hebron, J., \& Taylor, P. J. (2015b). The test-retest reliability of knee joint center location techniques. Journal of Applied Biomechanics, 31(2), 117-121.

24. Sinclair, J., \& Sant, B. (2017). The effects of cross-fit footwear on the kinetics and kinematics of running. Footwear Science, 9(1), 41-48.

25. Sinclair, J., Mann, J., Weston, G., Poulsen, N., Edmundson, C.J., Bentley, I., \& Stone, M. (2019). Acute effects of knee wraps/ sleeve on kinetics, kinematics and muscle forces during the barbell back squat. Sport Sciences for Health (In press https://link.springer.com/article/10.1007\%2Fs11332-019-00595-5).

26. Swinton, P.A., Lloyd, R., Keogh, J.W., Agouris, I., \& Stewart, A.D. (2012). A biomechanical comparison of the traditional squat, powerlifting squat, and box squat. The Journal of Strength \& Conditioning Research, 26(7), 1805-1816.

27. Van Eijden, T.M., Kouwenhoven, E., Verburg, J., \& Weijs, W.A. (1986). A mathematical model of the patellofemoral joint. Journal of biomechanics, 19(3), 219229. 
28. Vigotsky, A. D., Contreras, B., \& Beardsley, C. (2015). Biomechanical implications of skeletal muscle hypertrophy and atrophy: a musculoskeletal model. Peer J, 3, e1462.

29. Wagenmakers, E.J., Love, J., Marsman, M., Jamil, T., Ly, A., Verhagen, J., \& Meerhoff, F. (2018). Bayesian inference for psychology. Part II: Example applications with JASP. Psychonomic Bulletin \& Review, 25(1), 58-76.

30. Ward, S.R., Eng, C.M., Smallwood, L.H., \& Lieber, R.L. (2009). Are current measurements of lower extremity muscle architecture accurate? Clinical orthopaedics and related research, 467(4), 1074-1082.

31. Whitting, J.W., Meir, R.A., Crowley-McHattan, Z.J., \& Holding, R.C. (2016). Influence of footwear type on barbell back squat using 50, 70, and 90\% of one repetition maximum: A biomechanical analysis. The Journal of Strength \& Conditioning Research, 30(4), 1085-1092.

32. Willson, J.D., Sharpee, R., Meardon, S.A., \& Kernozek, T.W. (2014). Effects of step length on patellofemoral joint stress in female runners with and without patellofemoral pain. Clinical biomechanics, 29(3), 243-247.

33. Winwood, P.W., Keogh, J.W., \& Harris, N.K. (2012). Interrelationships between strength, anthropometrics, and strongman performance in novice strongman athletes. The Journal of Strength \& Conditioning Research, 26(2), 513-522.

\section{Acknowledgements}

We would like to thank UKSCA for their award of a research grant which allowed the experimental footwear to be purchased. In addition, we would like to acknowledge our institutional undergraduate internship

scheme

\section{(https://www.uclan.ac.uk/students/support/research/urip.php).}




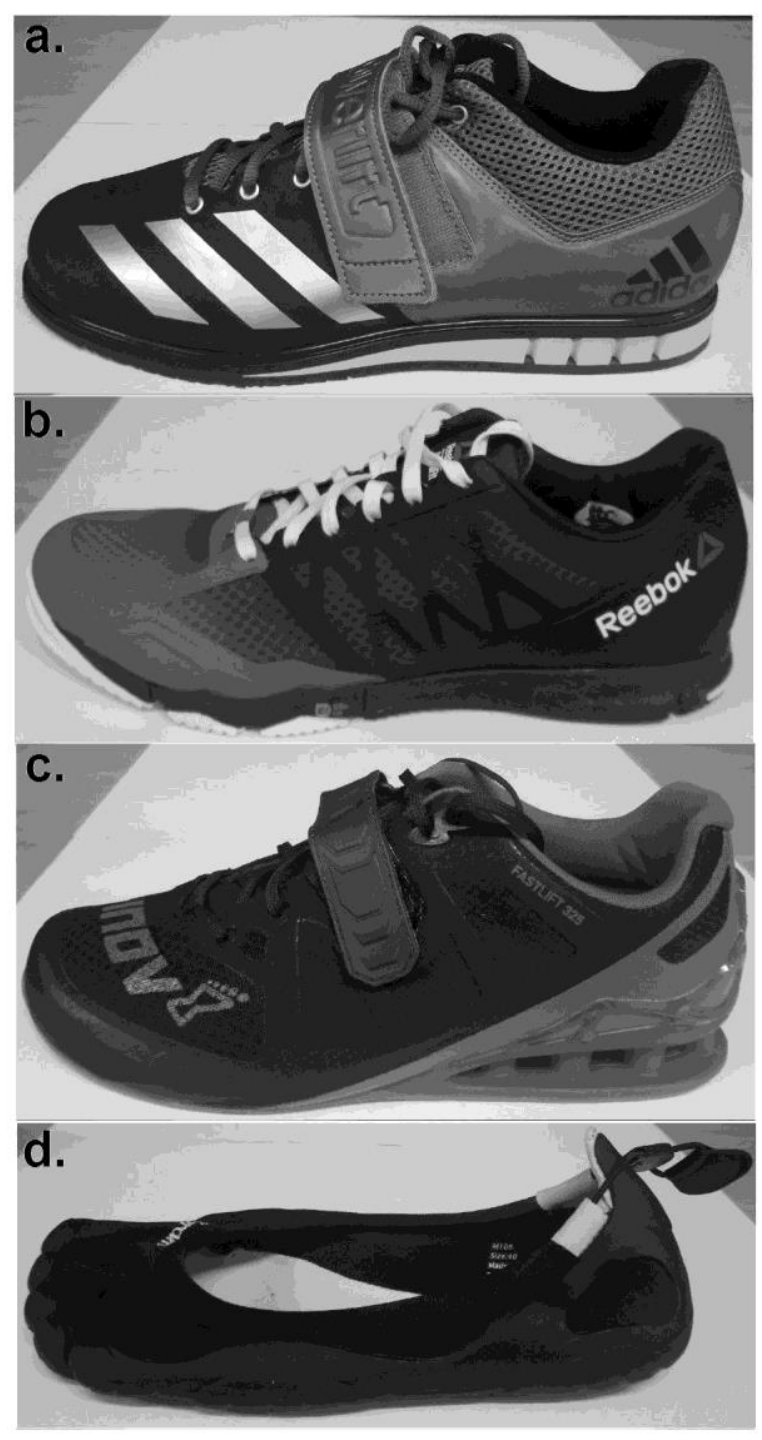

599

\section{$600 \quad$ List of figures}

601 Figure 1: Experimental footwear (a. Adidas, b. Cross-fit, c. Inov-8 and d. Minimal).

602 
Table 1: Kinetic and temporal parameters (Mean \pm SD) as a function of each FOOTWEAR and GENDER condition, Bayes factors for the FOOTWEAR (FW) and GENDER (G) main effects as well as the FOOTWEAR*GENDER $(F * G)$ interaction are presented.

\begin{tabular}{|c|c|c|c|c|c|c|c|c|c|c|c|c|c|c|c|c|c|c|c|}
\hline & \multicolumn{8}{|c|}{ Male } & \multicolumn{8}{|c|}{ Female } & \multirow{2}{*}{\multicolumn{3}{|c|}{ BF }} \\
\hline & \multicolumn{2}{|c|}{ Adidas } & \multicolumn{2}{|c|}{ Inov-8 } & \multicolumn{2}{|c|}{ Cross-fit } & \multicolumn{2}{|c|}{ Minimal } & \multicolumn{2}{|c|}{ Adidas } & \multicolumn{2}{|c|}{ Inov-8 } & \multicolumn{2}{|c|}{ Cross-fit } & \multicolumn{2}{|c|}{ Minimal } & & & \\
\hline & Mean & SD & Mean & SD & Mean & SD & Mean & SD & Mean & SD & Mean & SD & Mean & SD & Mean & SD & FW & G & $\mathbf{F}^{*} \mathbf{G}$ \\
\hline Peak vertical GRF (N/kg) & 13.83 & 2.82 & 14.06 & 2.84 & 13.98 & 2.87 & 12.90 & 2.11 & 12.88 & 1.77 & 12.74 & 2.06 & 13.07 & 2.00 & 12.72 & 1.87 & 8.67 & 0.74 & 1.83 \\
\hline $\begin{array}{c}\text { Eccentric medio-lateral GRF } \\
\text { integral }(\mathrm{N} / \mathrm{kg} \cdot \mathrm{s})\end{array}$ & -1.14 & 0.42 & -1.09 & 0.43 & -1.05 & 0.40 & -1.30 & 0.48 & -1.60 & 0.52 & -1.66 & 0.62 & -1.55 & 0.56 & -1.86 & 0.75 & 1864.28 & 2.51 & 0.20 \\
\hline $\begin{array}{c}\text { Eccentric anterio-posterior } \\
\text { GRF integral }(\mathrm{N} / \mathrm{kg} \cdot \mathrm{s})\end{array}$ & -0.10 & 0.15 & -0.06 & 0.21 & -0.04 & 0.14 & -0.08 & 0.15 & 0.03 & 0.13 & 0.03 & 0.11 & 0.02 & 0.13 & 0.00 & 0.17 & 0.22 & 0.85 & 0.36 \\
\hline $\begin{array}{l}\text { Eccentric vertical GRF } \\
\text { integral }(\mathrm{N} / \mathrm{kg} \cdot \mathrm{s})\end{array}$ & 11.00 & 2.27 & 10.61 & 2.00 & 10.57 & 2.16 & 11.61 & 3.18 & 11.34 & 3.46 & 11.38 & 3.43 & 11.47 & 3.53 & 12.12 & 4.39 & 5.67 & 0.67 & 0.16 \\
\hline $\begin{array}{c}\text { Concentric medio-lateral } \\
\text { GRF integral }(\mathrm{N} / \mathrm{kg} \cdot \mathrm{s})\end{array}$ & -1.20 & 0.33 & -1.21 & 0.37 & -1.16 & 0.36 & -1.34 & 0.38 & -2.11 & 0.59 & -2.23 & 0.71 & -2.03 & 0.59 & -2.30 & 0.62 & 41.21 & 125.05 & 0.24 \\
\hline $\begin{array}{c}\text { Concentric anterio- } \\
\text { posterior GRF integral } \\
(\mathrm{N} / \mathrm{kg} \cdot \mathrm{s})\end{array}$ & -0.18 & 0.15 & -0.15 & 0.15 & -0.14 & 0.12 & -0.19 & 0.10 & -0.10 & 0.17 & -0.09 & 0.17 & -0.08 & 0.17 & -0.09 & 0.14 & 0.53 & 0.80 & 0.21 \\
\hline $\begin{array}{l}\text { Concentric vertical GRF } \\
\text { integral }(\mathrm{N} / \mathrm{kg} \cdot \mathrm{s})\end{array}$ & 10.68 & 1.84 & 10.69 & 1.77 & 11.07 & 1.68 & 10.66 & 2.51 & 11.55 & 2.24 & 11.79 & 2.12 & 11.87 & 2.19 & 11.86 & 2.32 & 0.14 & 0.74 & 0.15 \\
\hline RFD (N/kg/s) & 51.34 & 23.78 & 59.62 & 24.77 & 45.87 & 19.25 & 52.52 & 32.41 & 48.06 & 18.80 & 41.72 & 21.45 & 38.84 & 12.08 & 47.16 & 18.12 & 0.75 & 0.67 & 0.52 \\
\hline Total time (s) & 2.29 & 0.37 & 2.23 & 0.34 & 2.27 & 0.38 & 2.41 & 0.43 & 2.40 & 0.37 & 2.44 & 0.39 & 2.46 & 0.41 & 2.53 & 0.47 & 15.31 & 0.75 & 0.24 \\
\hline Concentric time (s) & 1.14 & 0.18 & 1.12 & 0.18 & 1.16 & 0.20 & 1.17 & 0.21 & 1.21 & 0.14 & 1.24 & 0.15 & 1.26 & 0.17 & 1.26 & 0.17 & 0.43 & 0.95 & 0.20 \\
\hline Peak power (W/kg) & 18.28 & 4.11 & 18.99 & 4.23 & 18.63 & 4.00 & 17.07 & 3.58 & 15.87 & 2.29 & 15.26 & 2.87 & 15.16 & 2.31 & 15.41 & 2.16 & 0.32 & 1.56 & 3.19 \\
\hline Squat depth (\%) & 35.37 & 4.58 & 35.74 & 4.18 & 36.10 & 4.12 & 35.26 & 4.72 & 34.64 & 2.93 & 34.20 & 3.70 & 34.64 & 3.22 & 34.34 & 3.80 & 0.44 & 0.80 & 0.38 \\
\hline
\end{tabular}

Notes: medio-lateral GRF: + = lateral \& - = medial

Anterio-posterio GRF: + = anterior \& - = posterior 
Table 2: Muscle force parameters (Mean \pm SD) as a function of each FOOTWEAR and GENDER condition, Bayes factors for the FOOTWEAR (FW) and GENDER (G) main effects as well as the FOOTWEAR*GENDER $\left(F^{*} G\right)$ interaction are presented.

\begin{tabular}{|c|c|c|c|c|c|c|c|c|c|c|c|c|c|c|c|c|c|c|c|}
\hline & \multicolumn{8}{|c|}{ Male } & \multicolumn{8}{|c|}{ Female } & \multirow{2}{*}{\multicolumn{3}{|c|}{ BF }} \\
\hline & \multicolumn{2}{|c|}{ Adidas } & \multicolumn{2}{|c|}{ Inov-8 } & \multicolumn{2}{|c|}{ Cross-fit } & \multicolumn{2}{|c|}{ Minimal } & \multicolumn{2}{|c|}{ Adidas } & \multicolumn{2}{|c|}{ Inov-8 } & \multicolumn{2}{|c|}{ Cross-fit } & \multicolumn{2}{|c|}{ Minimal } & & & \\
\hline & Mean & SD & Mean & SD & Mean & SD & Mean & SD & Mean & SD & Mean & SD & Mean & SD & Mean & SD & FW & $\mathbf{G}$ & $F^{*} \mathbf{G}$ \\
\hline $\begin{array}{l}\text { Peak quadriceps force } \\
(\mathrm{N} / \mathrm{kg})\end{array}$ & 89.78 & 18.17 & 91.57 & 19.28 & 92.41 & 18.11 & 82.61 & 15.01 & 70.56 & 14.75 & 68.21 & 16.47 & 70.82 & 15.63 & 64.40 & 15.93 & 1440.89 & 6.61 & 0.59 \\
\hline $\begin{array}{c}\text { Quadriceps eccentric } \\
\text { impulse }(\mathrm{N} / \mathrm{kg} \cdot \mathrm{s})\end{array}$ & 54.05 & 12.88 & 53.05 & 12.21 & 54.19 & 12.15 & 55.48 & 16.02 & 44.90 & 13.58 & 43.75 & 14.28 & 46.40 & 14.50 & 45.69 & 16.59 & 0.27 & 0.69 & 0.08 \\
\hline $\begin{array}{l}\text { Quadriceps concentric } \\
\text { impulse }(\mathrm{N} / \mathrm{kg} \cdot \mathrm{s})\end{array}$ & 47.71 & 9.51 & 48.64 & 11.09 & 50.90 & 10.98 & 45.74 & 10.91 & 38.73 & 9.38 & 38.12 & 9.34 & 41.12 & 9.84 & 36.69 & 10.63 & 66.76 & 2.52 & 0.11 \\
\hline Quadriceps RFD (N/kg/s) & 105.99 & 87.35 & 106.99 & 63.81 & 131.21 & 116.02 & 280.13 & 592.03 & 78.58 & 34.93 & 109.40 & 143.49 & 73.22 & 40.09 & 74.75 & 32.48 & 0.17 & 0.53 & 0.43 \\
\hline $\begin{array}{l}\text { Peak hamstring force } \\
\text { (N/kg) }\end{array}$ & 49.18 & 10.52 & 52.48 & 12.04 & 49.70 & 9.58 & 47.20 & 11.88 & 44.18 & 9.82 & 44.65 & \begin{tabular}{|l|}
12.44 \\
\end{tabular} & 45.05 & 14.12 & 44.24 & 9.69 & 0.27 & 0.84 & 0.30 \\
\hline $\begin{array}{l}\text { Hamstring eccentric } \\
\text { impulse }(\mathrm{N} / \mathrm{kg} \cdot \mathrm{s})\end{array}$ & 20.08 & 4.76 & 20.83 & 3.97 & 20.02 & 4.12 & 21.29 & 9.94 & 19.51 & 6.16 & 20.24 & 5.91 & 19.51 & 6.85 & 21.15 & 8.08 & 0.26 & 0.58 & 0.11 \\
\hline $\begin{array}{l}\text { Hamstring concentric } \\
\text { impulse (N/kg.s) }\end{array}$ & 22.61 & 5.04 & 23.57 & 4.93 & 23.45 & 4.63 & 22.27 & 7.75 & 21.98 & 4.96 & 22.86 & 5.00 & 22.03 & 5.17 & 23.04 & 4.98 & 0.10 & 0.56 & 0.23 \\
\hline Hamstring RFD (N/kg/s) & 103.22 & 52.13 & 137.09 & 109.28 & 147.57 & 107.93 & 166.46 & 129.43 & 167.11 & 108.44 & 186.44 & 131.61 & 107.32 & 36.35 & 151.62 & 127.35 & 0.25 & 0.43 & 2.39 \\
\hline $\begin{array}{l}\text { Peak gluteus maximus } \\
\text { force }(\mathrm{N} / \mathrm{kg})\end{array}$ & 22.20 & 4.66 & 23.72 & 5.72 & 22.43 & 4.30 & 21.38 & 5.37 & 19.81 & 4.30 & 20.24 & 5.56 & 20.23 & 6.36 & 19.93 & 4.25 & 0.28 & 0.80 & 0.24 \\
\hline $\begin{array}{c}\text { Gluteus maximus } \\
\text { eccentric impulse }(\mathrm{N} / \mathrm{kg} \cdot \mathrm{s})\end{array}$ & 9.60 & 2.26 & 9.93 & 1.90 & 9.54 & 2.01 & 10.11 & 4.73 & 9.41 & 2.95 & 9.75 & 2.81 & 9.33 & 3.27 & 10.17 & 3.86 & 0.24 & 0.57 & 0.12 \\
\hline $\begin{array}{c}\text { Gluteus maximus } \\
\text { concentric impulse } \\
(\mathrm{N} / \mathrm{kg} \cdot \mathrm{s})\end{array}$ & 10.95 & 2.40 & 11.36 & 2.29 & 11.34 & 2.19 & 10.76 & 3.72 & 10.75 & 2.48 & 11.20 & 2.48 & 10.75 & 2.57 & 11.32 & 2.54 & 1.00 & 0.55 & 0.23 \\
\hline $\begin{array}{c}\text { Gluteus maximus RFD } \\
(\mathrm{N} / \mathrm{kg} / \mathrm{s})\end{array}$ & 50.59 & 23.33 & 67.13 & 47.94 & 71.62 & 49.75 & 84.55 & 62.58 & 82.39 & 48.12 & 87.74 & 142.25 & 57.04 & 15.79 & 77.46 & 54.90 & 0.41 & 0.45 & 1.17 \\
\hline $\begin{array}{l}\text { Peak gastrocnemius force } \\
\qquad(\mathrm{N} / \mathrm{kg})\end{array}$ & 7.50 & 1.57 & 7.20 & 1.91 & 7.59 & 1.38 & 6.92 & 1.97 & 6.32 & 1.69 & 6.19 & 1.87 & 6.11 & 1.84 & 6.34 & 2.13 & 0.11 & 1.04 & 0.48 \\
\hline $\begin{array}{l}\text { Gastrocnemius eccentric } \\
\text { impulse }(\mathrm{N} / \mathrm{kg} \cdot \mathrm{s})\end{array}$ & 4.53 & 1.52 & 3.94 & 1.88 & 4.21 & 1.43 & 4.01 & 2.31 & 3.68 & 1.91 & 3.79 & 1.38 & 3.63 & 1.65 & 3.85 & 2.11 & 0.09 & 0.63 & 0.38 \\
\hline
\end{tabular}




\begin{tabular}{|c|c|c|c|c|c|c|c|c|c|c|c|c|c|c|c|c|c|c|c|}
\hline $\begin{array}{c}\text { Gastrocnemius concentric } \\
\text { impulse }(\mathrm{N} / \mathrm{kg} \cdot \mathrm{s})\end{array}$ & 5.45 & 1.59 & 5.01 & 1.53 & 5.34 & 1.41 & 5.16 & 2.00 & 4.96 & 2.19 & 5.03 & 1.94 & 4.72 & 2.12 & 4.97 & 1.84 & 0.08 & 0.64 & 0.25 \\
\hline $\begin{array}{c}\text { Gastrocnemius RFD } \\
(\mathrm{N} / \mathrm{kg} / \mathrm{s})\end{array}$ & 24.45 & 5.31 & 23.56 & 4.73 & 22.61 & 4.34 & 40.05 & 60.92 & 29.29 & 8.04 & 26.33 & 14.74 & 36.46 & 17.10 & 25.80 & 10.90 & 0.11 & 0.30 & 0.55 \\
\hline Peak soleus force $(\mathrm{N} / \mathrm{kg})$ & 16.00 & 3.36 & 15.36 & 4.08 & 16.20 & 2.95 & 14.77 & 4.20 & 13.50 & 3.61 & 13.22 & 4.00 & 13.05 & 3.93 & 13.53 & 4.54 & 0.12 & 0.88 & 0.32 \\
\hline $\begin{array}{c}\text { Soleus eccentric impulse } \\
(\mathrm{N} / \mathrm{kg} \cdot \mathrm{s})\end{array}$ & 9.67 & 3.25 & 8.40 & 4.01 & 8.98 & 3.06 & 8.56 & 4.94 & 7.85 & 4.07 & 8.09 & 2.95 & 7.74 & 3.53 & 8.21 & 4.51 & 0.09 & 0.64 & \begin{tabular}{|l|l}
0.35 \\
\end{tabular} \\
\hline $\begin{array}{l}\text { Soleus concentric impulse } \\
(\mathrm{N} / \mathrm{kg} \cdot \mathrm{s})\end{array}$ & 11.63 & 3.40 & 10.69 & 3.26 & 11.39 & 3.01 & 11.02 & 4.28 & 10.60 & 4.68 & 10.74 & 4.15 & 10.08 & 4.54 & 10.60 & 3.94 & 0.08 & 0.65 & \begin{tabular}{|l|}
0.25 \\
\end{tabular} \\
\hline Soleus RFD (N/kg/s) & 52.19 & 11.34 & 50.29 & 10.11 & 48.26 & 9.26 & 85.49 & 130.06 & 62.53 & 17.15 & 56.21 & 31.47 & 77.84 & 36.51 & 55.08 & 23.27 & 0.11 & 0.29 & 0.59 \\
\hline
\end{tabular}


Table 3: Knee kinetic parameters (Mean \pm SD) as a function of each FOOTWEAR and GENDER condition, Bayes factors for the FOOTWEAR (FW) and GENDER (G) main effects as well as the FOOTWEAR*GENDER $\left(F^{*} G\right)$ interaction are presented.

\begin{tabular}{|c|c|c|c|c|c|c|c|c|c|c|c|c|c|c|c|c|c|c|c|}
\hline & \multicolumn{8}{|c|}{ Male } & \multicolumn{8}{|c|}{ Female } & & & \\
\hline & \multicolumn{2}{|c|}{ Adidas } & \multicolumn{2}{|c|}{ Inov-8 } & \multicolumn{2}{|c|}{ Cross-fit } & \multicolumn{2}{|c|}{ Minimal } & \multicolumn{2}{|c|}{ Adidas } & \multicolumn{2}{|c|}{ Inov-8 } & \multicolumn{2}{|c|}{ Cross-fit } & \multicolumn{2}{|c|}{ Minimal } & \multicolumn{3}{|c|}{ BF } \\
\hline & Mean & SD & Mean & SD & Mean & SD & Mean & SD & Mean & SD & Mean & SD & Mean & SD & Mean & SD & FW & G & $F * G$ \\
\hline Peak hip shear force (N/kg) & 6.47 & 1.40 & 6.42 & 1.18 & 6.39 & 1.21 & 6.68 & 2.38 & 6.32 & 1.93 & 6.41 & 1.99 & 6.44 & 2.02 & 6.76 & 2.50 & 0.22 & 0.62 & 0.13 \\
\hline Hip shear impulse $(\mathrm{N} / \mathrm{kg} \cdot \mathrm{s})$ & 13.09 & 2.46 & 13.18 & 2.17 & 13.32 & 2.10 & 13.12 & 4.01 & 12.84 & 2.71 & 13.10 & 2.74 & 13.19 & 2.96 & 13.42 & 3.18 & 0.08 & 0.59 & 0.12 \\
\hline $\begin{array}{l}\text { Hip shear loading rate } \\
(\mathrm{N} / \mathrm{kg} / \mathrm{s})\end{array}$ & 122.36 & 45.81 & 135.59 & 59.21 & 131.05 & 71.65 & 137.09 & 100.99 & 211.51 & 89.26 & 276.26 & 238.46 & 211.07 & 133.22 & 170.80 & 68.71 & 0.31 & 2.51 & 0.46 \\
\hline $\begin{array}{l}\text { Peak hip compressive force } \\
(\mathrm{N} / \mathrm{kg})\end{array}$ & 8.59 & 1.47 & 8.50 & 1.55 & 8.44 & 1.43 & 8.33 & 1.56 & 8.18 & 1.33 & 8.25 & 1.45 & 8.13 & 1.23 & 8.09 & 1.42 & 0.08 & 0.54 & 0.12 \\
\hline $\begin{array}{l}\text { Hip compressive impulse } \\
(\mathrm{N} / \mathrm{kg} \cdot \mathrm{s})\end{array}$ & 9.58 & 2.98 & 8.93 & 2.70 & 9.07 & 2.73 & 9.51 & 3.85 & 10.65 & 2.74 & 10.77 & 2.74 & 10.60 & 2.93 & 11.36 & 3.35 & 0.37 & 0.93 & 0.24 \\
\hline $\begin{array}{l}\text { Hip compressive loading rate } \\
(\mathrm{N} / \mathrm{kg} / \mathrm{s})\end{array}$ & 104.80 & 49.97 & 116.92 & 51.12 & 107.79 & 62.91 & 120.10 & 92.95 & 119.62 & 57.89 & 135.65 & 56.61 & 109.35 & 46.15 & 110.18 & 51.29 & 0.17 & 0.46 & 0.22 \\
\hline Peak knee shear force $(\mathrm{N} / \mathrm{kg})$ & 8.24 & 2.20 & 7.89 & 2.08 & 8.34 & 2.10 & 7.05 & 1.21 & 6.19 & 1.86 & 5.90 & 1.95 & 6.22 & 2.05 & 6.22 & 1.98 & 1.14 & 2.53 & 2.72 \\
\hline Knee shear impulse (N/kg·s) & 10.06 & 1.67 & 9.46 & 2.12 & 9.98 & 1.66 & 9.67 & 2.56 & 8.66 & 2.57 & 8.54 & 2.32 & 8.79 & 2.55 & 9.10 & 2.50 & 0.15 & 0.76 & 0.1 \\
\hline $\begin{array}{c}\text { Knee shear loading rate } \\
(\mathrm{N} / \mathrm{kg} / \mathrm{s})\end{array}$ & 47.48 & 33.38 & 45.38 & 22.13 & 49.68 & 20.95 & 48.64 & 16.03 & 40.03 & 9.10 & 64.04 & 77.29 & 41.96 & 9.21 & 46.26 & 8.03 & 0.12 & 0.30 & 0.33 \\
\hline $\begin{array}{l}\text { Peak knee compressive force } \\
\qquad(\mathrm{N} / \mathrm{kg})\end{array}$ & 10.67 & 2.19 & 11.20 & 2.24 & 10.88 & 2.18 & 10.16 & 2.20 & 10.68 & 1.36 & 10.70 & 1.64 & 10.72 & 1.56 & 10.53 & 1.36 & 1.22 & 0.57 & 0.37 \\
\hline $\begin{array}{l}\text { Knee compressive impulse } \\
(\mathrm{N} / \mathrm{kg} \cdot \mathrm{s})\end{array}$ & 17.48 & 3.63 & 17.47 & 2.89 & 17.49 & 3.18 & 17.94 & 5.36 & 19.24 & 4.23 & 19.65 & 4.29 & 19.61 & 4.61 & 20.20 & 5.14 & 0.17 & 0.76 & 0.22 \\
\hline $\begin{array}{l}\text { Knee compressive loading } \\
\text { rate }(\mathrm{N} / \mathrm{kg} / \mathrm{s})\end{array}$ & 59.11 & 23.32 & 66.61 & 20.67 & 57.79 & 15.08 & 65.61 & 19.76 & 58.39 & 14.63 & 58.81 & 26.34 & 48.40 & 10.33 & 53.07 & \begin{tabular}{|l|}
13.15 \\
\end{tabular} & 0.71 & 0.69 & 0.26 \\
\hline $\begin{array}{l}\text { Peak patellofemoral force } \\
\qquad(\mathrm{N} / \mathrm{kg})\end{array}$ & 50.90 & 10.56 & 51.71 & 11.18 & 52.51 & 10.45 & 46.54 & 8.66 & 39.42 & 8.51 & 37.99 & 9.46 & 39.67 & 8.90 & 36.02 & 9.17 & 1766.54 & 8.80 & 0.31 \\
\hline $\begin{array}{l}\text { Patellofemoral impulse } \\
(\mathrm{N} / \mathrm{kg} \cdot \mathrm{s})\end{array}$ & 55.58 & 10.31 & 55.50 & 11.23 & 57.50 & 10.80 & 55.20 & 12.18 & 45.20 & 10.92 & 44.15 & 11.11 & 47.29 & 11.49 & 44.44 & \begin{tabular}{|l|}
12.13 \\
\end{tabular} & 0.19 & 1.79 & 0.30 \\
\hline $\begin{array}{l}\text { Patellofemoral loading rate } \\
(\mathrm{N} / \mathrm{kg} / \mathrm{s})\end{array}$ & 184.99 & 67.58 & 194.89 & 76.44 & 207.95 & 70.33 & 213.39 & 98.26 & 131.45 & 29.02 & 155.17 & 83.03 & 139.98 & 32.64 & 142.42 & \begin{tabular}{|l|}
44.25 \\
\end{tabular} & 0.26 & 2.74 & 0.27 \\
\hline
\end{tabular}




\begin{tabular}{|c|c|c|c|c|c|c|c|c|c|c|c|c|c|c|c|c|c|c|c|}
\hline $\begin{array}{c}\text { Peak patellofemoral stress } \\
(\mathrm{KPa} / \mathrm{kg})\end{array}$ & 143.21 & 25.29 & 146.02 & 27.64 & 145.42 & 27.36 & 134.06 & 23.47 & 118.92 & 22.02 & 114.73 & 24.06 & 117.54 & 23.41 & 108.91 & 22.91 & 80.38 & 4.77 & 0.23 \\
\hline $\begin{array}{l}\text { Patellofemoral stress } \\
\text { impulse (KPa/kg.s) }\end{array}$ & 187.86 & 41.89 & 188.49 & 41.05 & 193.09 & 40.50 & 188.84 & 41.72 & 160.68 & 39.01 & 159.29 & 37.85 & 169.09 & 40.27 & 160.18 & 40.81 & 0.68 & 0.69 & 0.07 \\
\hline $\begin{array}{c}\text { Patellofemoral stress loading } \\
\text { rate }(\mathrm{KPa} / \mathrm{kg} / \mathrm{s})\end{array}$ & 639.74 & 213.83 & 670.26 & 198.56 & 696.68 & 180.65 & 703.75 & 225.04 & 547.42 & 63.53 & 615.32 & 351.79 & 510.98 & 60.79 & 552.51 & 97.82 & 0.11 & 1.34 & 0.30 \\
\hline $\begin{array}{c}\text { Peak patellar tendon force } \\
(\mathrm{N} / \mathrm{kg})\end{array}$ & 64.67 & 19.70 & 64.08 & 18.14 & 67.89 & 18.40 & 56.75 & 16.04 & 42.89 & 10.22 & 41.04 & 10.97 & 43.52 & 10.99 & 39.92 & 11.37 & 230.35 & 17.70 & 0.84 \\
\hline $\begin{array}{c}\text { Patellar tendon impulse } \\
(\mathrm{N} / \mathrm{kg} \cdot \mathrm{s})\end{array}$ & 67.33 & 13.40 & 67.20 & 14.46 & 69.99 & 14.04 & 67.18 & 15.57 & 54.34 & 13.09 & 53.63 & 13.13 & 57.03 & 13.72 & 53.97 & 14.24 & 1.13 & 1.91 & 0.10 \\
\hline $\begin{array}{l}\text { Patellar tendon loading rate } \\
\qquad(\mathrm{N} / \mathrm{kg} / \mathrm{s})\end{array}$ & 291.39 & 160.54 & 278.19 & 154.83 & 290.50 & 133.75 & 293.80 & 145.03 & 181.73 & 31.98 & 209.23 & 121.98 & 176.64 & 35.06 & 179.18 & 35.38 & 0.11 & 2.69 & 0.28 \\
\hline
\end{tabular}


Table 4: Three-dimensional parameters (Mean \pm SD) as a function of each FOOTWEAR and GENDER condition, Bayes factors for the FOOTWEAR (FW) and GENDER (G) main effects as well as the FOOTWEAR*GENDER ( $F * G)$ interaction are presented.

\begin{tabular}{|c|c|c|c|c|c|c|c|c|c|c|c|c|c|c|c|c|c|c|c|}
\hline \multirow[b]{3}{*}{ Trunk (sagittal plane) } & \multicolumn{8}{|c|}{ Male } & \multicolumn{8}{|c|}{ Female } & & & \\
\hline & \multicolumn{2}{|c|}{ Adidas } & \multicolumn{2}{|c|}{ Inov-8 } & \multicolumn{2}{|c|}{ Cross-fit } & \multicolumn{2}{|c|}{ Minimal } & \multicolumn{2}{|c|}{ Adidas } & \multicolumn{2}{|c|}{ Inov-8 } & \multicolumn{2}{|c|}{ Cross-fit } & \multicolumn{2}{|c|}{ Minimal } & \multicolumn{3}{|c|}{ BF } \\
\hline & Mean & SD & Mean & SD & Mean & SD & Mean & SD & Mean & SD & Mean & SD & Mean & SD & Mean & SD & FW & G & $F^{*} \mathbf{G}$ \\
\hline Peak flexion $\left({ }^{\circ}\right)$ & 36.47 & 3.84 & 37.04 & 4.47 & 36.21 & 4.89 & 37.41 & 4.11 & 41.54 & 9.61 & 43.19 & 12.07 & 41.13 & 10.49 & 43.94 & 12.27 & 150.82 & 1.63 & 0.47 \\
\hline $\operatorname{ROM}\left({ }^{\circ}\right)$ & 26.85 & 3.99 & 26.92 & 3.52 & 26.22 & 4.40 & 28.04 & 4.01 & 30.73 & 6.08 & 32.63 & 7.62 & 30.80 & 6.40 & 33.75 & 7.52 & 14436.20 & 1.27 & 0.54 \\
\hline \multicolumn{20}{|l|}{ Hip (sagittal plane) } \\
\hline Peak flexion & 92.63 & 10.86 & 94.29 & 11.06 & 94.86 & 10.53 & 92.96 & 11.98 & 87.76 & 7.06 & 87.59 & 8.50 & 89.10 & 8.04 & 86.42 & 9.82 & 2.46 & 1.09 & 0.11 \\
\hline $\operatorname{ROM}\left({ }^{\circ}\right)$ & 90.49 & 13.09 & 91.68 & 12.16 & 92.16 & 11.99 & 90.16 & 13.27 & 86.41 & 5.54 & 86.39 & 8.30 & 87.53 & 6.43 & 85.19 & 7.99 & 1.61 & 0.92 & 0.09 \\
\hline \multicolumn{20}{|l|}{ Hip (coronal plane) } \\
\hline Peak abduction $\left({ }^{\circ}\right)$ & -28.01 & 6.67 & -27.88 & 6.34 & -28.37 & 6.41 & -27.84 & 6.51 & -24.80 & 4.23 & -24.49 & 3.53 & -25.47 & 5.26 & -23.83 & 4.49 & 0.25 & 1.50 & 0.13 \\
\hline $\operatorname{ROM}\left({ }^{\circ}\right)$ & 19.47 & 4.78 & 19.44 & 5.10 & 19.47 & 5.73 & 19.23 & 5.14 & 16.77 & 3.32 & 16.42 & 3.07 & 17.71 & 4.34 & 16.20 & 4.03 & 0.2 & 0.96 & 0.23 \\
\hline \multicolumn{20}{|l|}{ Hip (transverse plane) } \\
\hline Peak internal rotation $\left(^{\circ}\right)$ & 16.38 & 11.29 & 16.01 & 11.38 & 17.32 & 11.36 & 15.36 & 10.62 & 10.89 & 6.08 & 11.54 & 6.23 & 11.32 & 6.12 & 10.58 & 7.15 & 0.43 & 0.67 & 0.35 \\
\hline $\operatorname{ROM}\left({ }^{\circ}\right)$ & 29.92 & 10.49 & 30.17 & 11.21 & 31.26 & 10.62 & 30.17 & 11.22 & 27.92 & 7.35 & 27.68 & 6.66 & 29.07 & 7.43 & 26.47 & 6.15 & 0.46 & 0.74 & 0.17 \\
\hline \multicolumn{20}{|l|}{ Knee (sagittal plane) } \\
\hline Peak flexion $\left({ }^{\circ}\right)$ & 129.04 & 12.15 & 127.74 & 11.63 & 130.96 & 10.51 & 126.65 & 12.57 & 115.32 & 10.17 & 114.19 & 11.37 & 116.62 & 10.46 & 114.52 & 12.06 & 8.15 & 4.88 & 0.17 \\
\hline $\operatorname{ROM}\left({ }^{\circ}\right)$ & 117.62 & 13.88 & 117.01 & 12.70 & 119.05 & 12.20 & 115.61 & 13.74 & 108.41 & 7.12 & 107.04 & 10.74 & 109.68 & 8.39 & 107.30 & 9.20 & 4.18 & 1.13 & 0.14 \\
\hline \multicolumn{20}{|l|}{ Knee (coronal plane) } \\
\hline Peak adduction $\left({ }^{\circ}\right)$ & 10.17 & 5.84 & 10.19 & 6.16 & 9.85 & 5.45 & 8.69 & 5.26 & 7.46 & 4.67 & 7.27 & 4.52 & 7.16 & 4.48 & 6.80 & 4.30 & 1.29 & 0.76 & 0.18 \\
\hline $\operatorname{ROM}\left({ }^{\circ}\right)$ & 8.23 & 5.90 & 8.88 & 6.59 & 8.29 & 5.53 & 7.57 & 5.58 & 9.50 & 4.05 & 9.14 & 3.86 & 9.38 & 3.91 & 8.59 & 3.47 & 0.66 & 0.71 & 0.20 \\
\hline \multicolumn{20}{|l|}{ Knee (transverse plane) } \\
\hline Peak internal rotation $\left(^{\circ}\right)$ & 20.51 & 10.60 & 20.21 & 10.31 & 20.92 & 10.37 & 19.37 & 10.12 & 10.43 & 7.08 & 9.14 & 8.28 & 10.25 & 6.84 & 8.91 & 7.74 & 0.77 & 3.16 & 0.13 \\
\hline $\operatorname{ROM}\left({ }^{\circ}\right)$ & 24.11 & 12.54 & 23.77 & 11.52 & 23.55 & 12.20 & 21.85 & 12.02 & 13.95 & 8.74 & 13.27 & 10.83 & 13.33 & 9.22 & 12.52 & 10.10 & 0.35 & 1.32 & 0.10 \\
\hline \multicolumn{20}{|l|}{ Ankle (sagittal plane) } \\
\hline Peak dorsiflexion $\left({ }^{\circ}\right)$ & 28.32 & 5.31 & 26.88 & 7.13 & 26.96 & 4.78 & 27.61 & 5.39 & 23.67 & 4.66 & 22.86 & 5.78 & 21.57 & 4.84 & 25.49 & 3.93 & 2.66 & 1.63 & 0.56 \\
\hline $\operatorname{ROM}\left({ }^{\circ}\right)$ & 29.39 & 3.33 & 27.25 & 4.34 & 29.76 & 2.78 & 27.36 & 3.34 & 25.25 & 3.12 & 22.58 & 4.10 & 25.24 & 3.39 & 23.71 & 4.13 & 6.80 & 2489.66 & 0.51 \\
\hline \multicolumn{20}{|l|}{ Ankle (coronal plane) } \\
\hline Peak eversion $\left({ }^{\circ}\right)$ & -8.02 & 5.54 & -7.55 & 4.51 & $\begin{array}{l}-7.78 \\
\end{array}$ & 5.14 & -7.90 & 4.96 & -4.21 & 4.42 & -5.10 & 4.39 & -4.50 & 5.28 & -5.12 & 4.91 & 0.07 & 1.05 & 0.13 \\
\hline
\end{tabular}




\begin{tabular}{|c|c|c|c|c|c|c|c|c|c|c|c|c|c|c|c|c|c|c|c|}
\hline $\operatorname{ROM}\left({ }^{\circ}\right)$ & 8.89 & 5.11 & 9.19 & 4.31 & 8.68 & 4.62 & 9.37 & 4.32 & 5.95 & 4.05 & 6.41 & 3.70 & 6.35 & 3.53 & 6.23 & 3.71 & 0.09 & 0.93 & 0.15 \\
\hline \multicolumn{20}{|l|}{ Ankle (transverse plane) } \\
\hline Peak external rotation $\left({ }^{\circ}\right)$ & -3.48 & 3.90 & -6.05 & 6.02 & -2.16 & 5.60 & -8.41 & 6.65 & -4.61 & 4.32 & -6.14 & 4.65 & -3.63 & 4.02 & -8.57 & 4.78 & 2765.88 & 0.49 & 0.20 \\
\hline $\operatorname{ROM}\left({ }^{\circ}\right)$ & 6.74 & 2.75 & 7.96 & 3.28 & 6.98 & 3.29 & 7.96 & 2.60 & 7.40 & 3.74 & 7.22 & 3.67 & 7.50 & 3.99 & 7.35 & 3.32 & 0.06 & 1.03 & 0.27 \\
\hline
\end{tabular}

